\title{
AS POPULAÇÕES DAS MINAS GERAIS NO SÉCULO XVIII: Um Estudo de Demografia Histórica
}

\section{THE POPULATIONS OF THE MINAS GERAIS IN THE EIGHTEENTH CENTURY: \\ A Study of Historical Demography}

Iraci del Nero da Costa

Para Tito, amigo inesquecível.

\begin{abstract}
RESUMO: Depois de se contemplar os condicionantes do estabelecimento, apogeu e queda da extração aurífera em Minas Gerais, analisa-se o evolver do comportamento quantitativo, no correr do período 1719-1826, dos casamentos, óbitos e batismos concernentes à Freguesia de Nossa Senhora da Conceição de Antônio Dias, uma das duas paróquias então existentes em Vila Rica, hoje Ouro Preto. Ademais, é estabelecida a relação entre tais variáveis demográficas e as vicissitudes de ordem econômica vivenciadas pelos habitantes da urbe.
\end{abstract}

Palavras chave: Mineração, Demografia Histórica, Evolução demográfica de Vila Rica (MG).

ABSTRACT: After reviewing the establishment, rise and fall of gold mining in Minas Gerais, the author examines the evolution, in the course of the period 1719-1826, of the marriages, deaths and baptisms in the Parish "Nossa Senhora da Conceição de Antonio Dias", one of two parishes then existing in Vila Rica. Also it is established the relationship between the demographic variables and the economic evolution of the village.

Keywords: Gold Mining, Historical Demography, Demographic evolution of Vila Rica (MG).

\section{INTRODUÇÃO}

O evolver da população brasileira no período colonial condicionou-se por uma larga série de fatores, tanto endógenos como exógenos. Com respeito a estes últimos ressalta, desde logo, o direcionamento político e econômico a que se destinou a Colônia.

Como sabemos, o povoamento e valorização do Brasil ocorreram nos quadros das políticas mercantilistas. Assim, quando nos debruçamos sobre nossa formação populacional devemos reconhecer, forçosamente, não tratarmos de simples repetição dos processos verificados na Europa ou em países mais desenvolvidos.

Para nosso período colonial reputamos altamente relevante a existência da economia de exportação ao lado da de subsistência. A rentabilidade daquela condicionava-se pelos preços

\footnotetext{
- Professor Livre-docente aposentado da Universidade de São Paulo. Coordenador do Núcleo de Estudos em História Demográfica de Professores da Faculdade de Economia, Administração e Contabilidade da USP.
} 
vigentes no mercado internacional. Considerada a oferta elástica do fator terra e a relativa facilidade com que se podia realocar a mão de obra escrava da atividade exportadora para a de subsistência, espera-se que os freios malthusianos ao crescimento vegetativo da população jamais tenham assumido papel grandemente significativo no Brasil.

Por outro lado, as condições do mercado e dos preços internacionais para os produtos exportados podiam afetar o ritmo das atividades voltadas para a produção de gêneros de primeira necessidade. Destarte, provavelmente, as respostas da oferta de alimentos básicos aos estímulos do mercado interno vinculavam-se estreitamente aos incentivos gerados na órbita do comércio internacional. Fato a exercer papel fundamental na alocação da força de trabalho, dos recursos produtivos e, sobretudo, nos processos de dispersão e convergência populacionais; a influir decisivamente, portanto, nos movimentos migratórios internos.

A articulação da economia colonial na economia europeia vai, igualmente, condicionar os fluxos imigratórios tanto dos reinóis como da escravaria negra trazida da África. Do ponto de vista endógeno salientam-se, primacialmente, o meio físico, a dotação relativa de fatores e a ocorrência de insumos, bem como as formas assumidas na produção ou na extração das riquezas naturais. Como decorrência desta última observação, põe-se o problema referente à existência, no período em análise, de segmentos populacionais - livres, forros e escravos - distintos dos prevalecentes na Europa e que, certamente, apresentaram dinâmica própria.

\section{O PERÍODO ANALISADO E A ATIVIDADE MINERATÓRIA EM MINAS GERAIS}

O período em foco - da segunda década do século XVIII ao primeiro quartel da décima nona centúria - abrange, com respeito à área das Minas Gerais, o surto mineratório, seu auge e decadência, captando as repercussões sociais e econômicas do reflorescimento agrícola na Colônia, cujas raízes assentaram-se no último quartel do século dezoito. Compreende, igualmente, a concentração populacional ocorrida nos três primeiros quartos do século XVIII, período no qual se formou o estoque de população que, em segundo momento, também englobado pelo estudo vertente, dirigiu-se para outras áreas do território brasileiro.

Vemos ocorrer, portanto, o fluxo e refluxo populacional, vale dizer, a concentração de grande contingente humano - oriundo dos diversos quadrantes do Brasil, da metrópole e demais dependências coloniais - em pequeno espaço territorial e sua subsecutiva diáspora. Estes 
movimentos foram condicionados, de um lado, pela ascensão e recesso da atividade aurífera e, de outro, pelas atividades econômicas subsequentes à decadência da mineração.

Dificilmente poder-se-ia superestimar a importância do período mineratório na formação socioeconômica do Brasil. A atividade aurífera levou à ocupação do interior brasileiro; os limites teóricos fixados em Tordesilhas foram largamente ultrapassados. As áreas de ocorrência do ouro, afastadas do litoral e de baixa densidade populacional, passaram a exercer tamanha atração sobre 0 espírito dos reinóis e colonos que, em pouco mais de noventa anos, a população viu-se decuplicada, concentrando-se no centro-sul - área que apresentava, anteriormente, baixíssima densidade demográfica - cerca de cinquenta por cento do contingente humano da Colônia.

A interligação das áreas já ocupadas pelo colonizador europeu aparecia como primeiro elemento de integração econômica e social, ao mesmo tempo esboçava-se o mercado consumidor interno e intensificava-se o processo de urbanização.

Paralelamente, ocorriam mudanças significativas na administração colonial, maior vigor e fortalecimento do Estado faziam-se necessários para controlar a economia, a cada passo mais complexa, e enquadrar uma população a crescer aceleradamente.

A região das Minas Gerais desenvolveu-se no século XVIII como centro de intensa atividade, cuja influência se fez sentir nas várias economias da Colônia. Dos mais importantes é o fato de que o desenvolvimento da mineração deu-se concomitantemente à decadência da lavoura, atividade que até então havia monopolizado as energias do colonizador luso.

\title{
Como diz Alice Piffer Canabrava:
}

\begin{abstract}
"A economia colonial brasileira havia-se desenvolvido, até então, na zona litorânea. Os engenhos de açúcar ocupavam uma faixa de solos ricos, primitivamente cobertos de florestas, que abrangia apenas 30 a $60 \mathrm{~km}$ junto ao mar. As notícias que se propagavam sobre as descobertas nas gerais, os rendimentos consideráveis das pintas atraíram para aquela área elementos da população de todas as partes da Colônia. o entusiasmo contagiou todas as camadas sociais. Nas frotas comprimiam-se centenas de reinóis e até estrangeiros se infiltraram nas entradas de roldão dos primeiros anos. $O$ fenômeno, comum historicamente quanto ao papel polarizador de população dos achados auríferos, deslocou rapidamente para o interior da colônia o centro de gravidade do povoamento, localizado até então no litoral leste."1
\end{abstract}

A ocupação e povoamento das Minas Gerais se nos apresentam, em larga medida, regulados pelas condições em que se exploraram o ouro e as pedras preciosas. Em cada momento relacionam-se as condições geográficas, de um lado, e a forma de recolhimento das riquezas 
minerais, por outro.

Os depósitos de aluvião - produto da atividade milenar das águas - a par de se esgotarem com rapidez, são facilmente exploráveis; este fenômeno levou as primeiras atividades extrativas a se localizarem nos rios, com o mínimo de aparelhagem, dependendo, a produção alcançada, do trabalho de maior ou menor número de escravos. Mesmo os "rosários" - almanjarras que põe a seco trechos previamente cercados dos rios - não constituíram utensilagem capaz de impedir 0 nomadismo dos mineradores. A exploração a seco efetuava-se rapidamente entre as estações de chuvas, pois as águas, engrossadas, arrebentavam as ensecadeiras inundando e destruindo o que se thes anteparava. A falta de continuidade nos trabalhos vinha a facilitar 0 abandono de uma exploração por outra com maiores perspectivas de ganho.

Durante esta primeira fase 0 explorador vivia nômade e a população apresentava-se extremamente diluída. Concentrados na atividade mais rentável, os mineradores deixavam-se absorver completamente pelo trabalho nas aluviões; os períodos de grandes fomes, sincrônicos com a alta dos preços, geraram-se pela concentração dos recursos na tarefa mineratória. A falta de gêneros propiciou a primeira convergência das atividades até então esparsas e ensejou os grandes acampamentos ao longo dos rios. Estes primeiros núcleos se abasteciam por tropas oriundas da Bahia, São Paulo e Rio de Janeiro.

À medida que escasseava o ouro de aluvião os mineradores, antes limitados a explorar 0 leito dos rios, passaram a procurá-lo nos "tabuleiros", à margem daqueles, onde abriram as primeiras catas. Esta atividade mais complexa não conseguiu, contudo, fixar o homem; continuavase a viver em acampamentos, abandonados tão cedo quanto migravam as catas.

Durante cerca de trinta anos explorou-se, apenas, o ouro de lavagem e abriram-se catas nos tabuleiros. Os primeiros povoados viviam a fase embrionária caracterizada pelo comércio feito por tropas e com o concurso dos mascates.

Logo as explorações começaram a subir pelas encostas dos morros a procura de ouro nas aluviões de meia encosta, as chamadas "grupiaras". Somente a partir deste momento o trabalho tendeu a estabilizar-se. Seu denominador comum foram as primeiras "catas altas", verdadeiras lavras pelo movimento de terra nelas efetuado. No morro - onde inicialmente apenas se trabalhava na época das chuvas, pois as águas avolumadas impossibilitavam a atividade junto aos rios - 
concentraram-se os trabalhos, que se multiplicaram na razão direta do esgotamento dos leitos dos rios.

As explorações na meia encosta necessitavam de água conduzida por canais que se estendiam por quilômetros. Surge em 1720 o Regimento das Águas e a guardamoria passa também a conceder datas de "águas minerais". Os regos, a contornar vales, a atravessar morros, a correr sobre extensos "andaimes" de pedra empilhada, são verdadeiros aquedutos; os "mundéus" reservatórios enormes - aparecem como trabalhos de vulto a reclamar significativos investimentos em capital fixo. A exploração das grupiaras exigia estabilidade populacional e operava no sentido de consolidar os povoados anteriormente esboçados.

A partir de 1720 restavam poucos descobertos a fazer nos rios. Os mineiros, sem necessitar de novas concessões, subiram pelas encostas dos vales, junto às suas datas, até atingir 0 alto dos morros. Os trabalhos vultosos que o ouro de montanha exigia revelavam-se incompatíveis com a atividade errante dos primeiros tempos. Os homens passaram a radicar-se à terra. Organizava-se a sociedade, a justiça civil começava a firmar-se. Desde 1720 grande parte da população das Minas já não vivia nômade. A concentração e a estabilidade dos trabalhos levaram os senhores a construir suas casas próximo às minerações e constituíram-se as primeiras famílias regulares.

Junto às primeiras lavras, com o tempo, desapareceram as primitivas "casas de sopapo". Em seu lugar os mineradores levantaram seus casarões. Paralelamente, estruturavam-se os povoados como centro de gravidade das zonas mais ricas, neles os tropeiros podiam mais facilmente estabelecer-se como comerciantes; tais lugarejos aparecem como retaguarda imediata do trabalho mineratório. O local da primitiva Capela - situada em cima do morro, bem à vista das várias minerações - já não servia como núcleo para as vilas em desenvolvimento. 0 casario desceu para 0 vale a procura de local mais apropriado ao seu crescimento.

No povoado, aos domingos, começou a estruturar-se a vida em comunidade. As pessoas apresentavam-se nas festas religiosas incorporadas às respectivas confrarias e cada qual se esforçava para dar à sua irmandade mais prestígio e brilho. Depois da missa percorriam as casas de comércio e faziam as compras para toda a semana. Os primeiros povoados chamaram-se "arraiais" - nome que em Portugal se dava ao acampamento, à reunião festiva do povo quando das romarias.

Em cada área de maior densidade de mineração surgiu um núcleo urbano. Os senhores das lavras acabaram por se instalar nestes povoados, embora continuassem a manter suas residências 
nas lavras. Os arraiais, oriundos da fixação do comércio ambulante, avolumaram-se com o duplicar das moradas. Na casa da cidade, o minerador habitava, quando a negócios. As construções mantiveram-se estritamente citadinas, sem jardins, árvores ou alpendre. As casas, sem luxo, alinhavam suas fachadas bem sobre a rua.

A atividade exploratória operou, ainda, no sentido de articular, caracteristicamente, as relações entre senhores e cativos. Embora fadados a existência árdua e, por vezes, breve resultante da labuta a que se os destinava - podiam esquivar-se de muitos maus tratos dada a possibilidade de utilizarem, contra seus donos, a arma da denúncia de fraudes fiscais; qualquer delação, mesmo infundada, podia causar sérios transtornos.

Por outro lado, o rendimento das lavras dependia, em grande parte, da diligencia e boa vontade do trabalhador. Os escravos mais produtivos recebiam prêmios; havia senhores que, ao fim de umas tantas gramas apuradas pelo escravo, consentiam que este trabalhasse o resto do dia para o seu próprio proveito. Nos contratos diamantíferos, o escravo que achasse um diamante de certo tamanho podia obter a liberdade. Em face do número crescente de alforrias a coroa adotou medidas inibitórias desta prática.

Em Minas, defrontamo-nos com realidade diversa daquela das áreas voltadas precipuamente para a atividade agrícola; como diz Celso Furtado:

\footnotetext{
"Se bem que a base da economia mineira também seja o trabalho escravo, por sua organização geral ela se diferencia amplamente da economia açucareira [...] a forma como se organiza o trabalho permite que o escravo tenha maior iniciativa e que circule num meio social mais complexo [...] Muitos escravos chegam mesmo a trabalhar por conta própria, comprometendo-se a pagar periodicamente uma quantia fixa a seu dono, o que lhes abre a possibilidade de comprar a própria liberdade."2
}

O ouro condicionava, igualmente, o tônus e o ritmo da sociedade mineira. 0 próprio juízo que se alcançava da vida social e das instituições a ele relacionava-se; movimento similar dá-se com respeito à percepção do meio físico circundante.

A euforia gerada pelos novos e contínuos descobertos, pela afluência, consubstanciaramse, por exemplo, no Triunfo Eucarístico, esfuziante símbolo da unidade de pensamento e ação de uma comunidade rica e em processo de crescimento econômico. Nele, Simão Ferreira Machado relata as festividades associadas à inauguração, em 1733, da nova matriz de Nossa Senhora do Pilar e a transferência para ela da Eucaristia, depositada que estivera em outra igreja. Quanto à urbe 
(Ouro Preto), assim a via o cronista:

"Nesta vila habitam os homens de maior comércio, cujo tráfego e importância excede sem comparação o maior dos maiores homens de Portugal: a ela, como a porto, se encaminham, e recolhem as grandiosas somas de ouro de todas as minas na Real Casa da Moeda: nela residem os homens de maiores letras, seculares, e eclesiásticos: nela tem assento toda a nobreza, e força da milícia; é por situação da natureza cabeça de toda a América, pela opulência das riquezas a pérola preciosa do Brasil."3

Já outro espírito nota-se no Áureo Trono Episcopal, relato da posse, em 1748, de Dom Frei Manuel da Cruz como primeiro bispo da diocese de Mariana, criada que fora em 1745. 0 autor, anônimo, pinta-nos o quadro das Minas Gerais nos meados do século XVIII: "... sem embargo de ser tanta a decadência do mesmo país, que por acaso se acha nele quem possa com o dispêndio necessário para a conservação de sua pessoa, e fábricas."4

A crise aprofundava-se; em Tomás Antônio Gonzaga - 1786/89 - adverte-se, de um lado, nostalgia, por outro, revolta. Com o ouro a esgotar-se, acabam a bonomia, o fastígio; resta a crítica dos costumes, das práticas, do sistema - a Inconfidência.

A situação de outrora, do ouro aluvionário, é decantada:

"Em quanto, Dorotheo, a nossa Chile

Em toda a parte tinha à flor da terra

Extensas, e abundantes minas de oiro

Então, prezado amigo, em qualquer festa

Tirava liberal o bom Senado

Dos cofres chapeados grossas barras." 5

Enquanto as dívidas para com a Coroa aumentavam, os exatores mostravam-se mais inflexíveis:

"Pretende, Dorotheo, o nosso chefe

Mostrar um grande zelo nas cobranças

Do imenso cabedal, que todo o povo

Aos cofres do Monarca, está devendo:

Envia bons soldados às Comarcas,

E manda-lhes, que cobrem, ou que metam

A quantos não pagarem nas Cadeias"6

O encanto chegara ao fim - Vila Rica - "pela opulência das riquezas a pérola preciosa do

2 FURTADO, 1970, p. 75.

3 MACHADO, 1734, p. 24-25.

${ }^{4}$ ANÔNIMO, 1749 , p. 35.

5 GONZAGA, Cartas Chilenas, Carta 5a., versos 52/54, 65/67.

6 GONZAGA, Cartas Chilenas, Carta 7a., versos 202/208. 
Brasil" - transformara-se em "pobre Aldeia", "terra decadente", "Humilde povoado, onde os Grandes/Moram em casas de madeira a pique."7

Depois de algumas décadas de intensa produção aurífera, no meado do século XVIII, as minas começaram a exaurir-se. 0 produto das jazidas vê-se reduzido, a Coroa, por seu lado, negava-se a reformular a sistemática tributária.

Nas minas, exploravam-se os depósitos superficiais rapidamente esgotáveis. As reservas de aluvião extinguiam-se com brevidade; nos morros chegava-se à rocha dura. Para os trabalhos subterrâneos - a nosso ver de duvidosa rentabilidade - faltavam capitais e, sobretudo, técnicas.

No último quartel do século XVIII a decadência generalizou-se. Os mineiros passaram a procurar as poucas áreas de terra fértil na região das Minas ou dirigiram-se para leste - Zona da Mata, de terras mais ricas -, para as áreas de plantio do sul ou demandaram os campos criatórios situados a oeste.

Superava-se uma fase da vida econômica colonial, as atenções voltavam-se, redobradamente, para a atividade agrícola. Conforme Caio Prado Júnior:

\begin{abstract}
"Este renascimento agrícola da colônia se faz em contraste frisante com as regiões mineradoras, cujo declínio se torna cada vez mais acentuado. Elas se voltam aliás, na medida do possível, para as atividades rurais. Vimos já como a cultura do algodão ai se desenvolve; a pecuária também adquire importância excepcional, e em Minas Gerais se constituirá o centro criador de mais alto nível na Colônia."8
\end{abstract}

Particularmente o preparo de laticínios, que antes não se praticava no Brasil em escala comercial, torna-se notável.

O queijo aí produzido tornou-se famoso, e até hoje é o mais conhecido do país (o queijo de Minas). Forma-se também, no sul de Minas Gerais, uma região de cultura do tabaco que, embora nunca chegue a rivalizar com a Bahia, teve sua importância,

A paisagem das velhas cidades, construídas enquanto cresciam os mananciais de riqueza, com suas belas igrejas barrocas, os sobradões debruçados diretamente sobre as ruas estreitas, as praças apertadas, os chafarizes outrora borbulhantes, lá estão hoje, preservados no tempo como mensagem histórica a documentar a realidade social vivida no passado. A decadência muito rápida, a excelência dos materiais, não deram margem à deterioração, às marcas da miséria a se arrastar ao longo dos anos, frutos de paulatino apoucar de recursos.

7 GONZAGA, Cartas Chilenas, Carta 3a., versos 123, 85 e 89/90. 


\section{VILA RICA NO INÍCIO DO SÉCULO XIX}

Antes de passarmos à análise dos dados populacionais referentes à paróquia de Nossa Senhora da Conceição de Antônio Dias - uma de duas existentes em Ouro Preto no período colonial - esboçaremos o perfil de Vila Rica como se apresentava ao início do século XIX. O quadro desta área mineira, no alvorecer do século XIX revelava-se desolador. Superada a "febre" do ouro a economia estagnou-se e apresentava-se, nos núcleos urbanos, franca recessão populacional. Nos seus arredores descortinavam-se campos desertos, sem lavouras ou rebanhos. Dos morros, esgaravatados até a rocha, havia-se eliminado a vida vegetal; neles restavam montes de cascalho e casas, na maioria, em ruínas.

A pobreza dos habitantes remanescentes, a existência de ruas inteiras quase abandonadas provocavam imediata admiração nos visitantes que passavam por Vila Rica. Das duas mil casas na sua maioria construídas de barro e mal conservadas, a atestar os parcos recursos de seus donos -, quantidade considerável não estava ocupada, o aluguel mostrava-se cadente; nas transações imobiliárias a queda dos preços alcançou 50\%. A população que somara, como atesta Saint-Hilaire, vinte mil pessoas, reduzira-se a oito milhares; tal quebra no número de habitantes teria sido ainda maior, não fosse Vila Rica a capital da capitania, centro político-administrativo e residência de um regimento.

A acompanhar a decadência geral deteriorava-se, também, a assistência educacional e hospitalar. O Seminário de Mariana, fundado com ajuda de mineiros ricos para educar seus filhos sem que fosse necessário enviá-los à Europa, não conseguia sobreviver à crise, as terras que a entidade possuía esgotaram-se, os escravos morreram; os mineradores, cuja riqueza minguara, não mais podiam sustentar o educandário.

Segundo Saint-Hilaire "era o momento de as autoridades eclesiásticas e civis se reunirem para vir em socorro de um estabelecimento tão útil à província... porém... achou-se mais cômodo fechar o seminário. ${ }^{9}$

O mesmo autor deplorava, ainda, que - numa capitania onde despendera-se grande soma de dinheiro na ereção de templos religiosos - o único hospital fosse mantido pela Irmandade de Misericórdia, sem contar com apoio governamental. 
A atividade manufatureira, proibida durante largo espaço de tempo, revelava-se tímida. Existiam na urbe e suas proximidades, tão somente, a manufatura de pólvora, pertencente ao governo, e uma fabrica de louça, estabelecida a pequena distância de Vila Rica.

Ao que parece, o comércio e atividades artesanais compunham os elementos de sustentação econômica de Vila Rica. Conforme John Mawe, poucos habitantes, excetuados os lojistas, tinham de que se ocupar; as casas comerciais voltadas para a venda dos produtos da área revelavam-se pobres e em pequeno número. Existia, como já referimos e ficará patenteado no correr deste trabalho, quantidade substancial de artesãos: alfaiates, costureiras, sapateiros, latoeiros, seleiros etc.

Por outro lado, a lavoura, atividade a ressurgir, não se desenvolveu como poderia ter ocorrido em decorrência, ao que parece, do despreparo e mentalidade do colonizador.

Não devemos afastar, aqui, o possivel europocentrismo que informava as opiniões dos viajantes estrangeiros no referente às críticas tecidas aos coloniais. Segundo os aludidos visitantes, o desemprego, em Vila Rica, decorria do desprezo dos habitantes pela "bela região que os cerca"; as terras, caso devidamente cultivadas, compensariam com generosidade o esforço despendido. Conforme diagnosticaram, a educação, hábitos e preconceitos hereditários tornaram os coloniais inaptos para a vida ativa. A perspectiva do enriquecimento súbito, devido ao acaso, operaria no sentido de afrouxar a capacidade produtiva. Por outro lado, mostrar-se-ia generalizada a incapacidade gerencial dos donos de escravos. Segundo John Mawe:

\begin{abstract}
"os negros constituem sua principal propriedade e ele os dirige tão mal que os lucros do trabalho deles raramente compensam as despesas de sua manutenção; com o decorrer do tempo tornam-se velhos e incapazes de trabalhar; ainda assim o senhor continua a viver na mesma negligência e na ociosidade [...] Esta degeneração deplorável constitui o traço característico da maior parte dos descendentes dos primeiros colonos; todas as espécies de indústria estão nas mãos ou dos mulatos ou dos negros; estas duas classes de homens parecem exceder em inteligência a seus senhores, porque fazem melhor uso dessa faculdade."10
\end{abstract}

Conforme 0 autor citado a área oferecia condições favoráveis a várias culturas: pereira, oliveira, amoreira, vinha, milho e trigo. 0 gado, por sua vez, se bem tratado e fornido de alimentação adequada, propiciaria o estabelecimento de promissora indústria de laticínios.

Para vários autores a diáspora que assistimos no final do século XVIII deveu-se, pois, em grande parte, à disposição dos coloniais. Sem o propósito de apresentar o balanço minucioso das 
causas da decadência econômica da área mineratória e a decorrente "expulsão" populacional, permitimo-nos, como mera conjectura, arrolar os principais condicionantes do aludido recesso. À exaustão dos depósitos mais ricos de ouro somaram-se o meio físico relativamente adverso, a inexistência de mercados significativos e boas vias de transportes, despreparo no que diz respeito a técnicas mais sofisticadas para trabalhar o solo, bem como a mentalidade do colonizador que desprezava o trabalho manual e rotineiro, em geral, e a faina agrícola em particular.

Tais condições compeliram os mineiros à seguinte alternativa: demandar novas áreas, onde predominariam por muito tempo as atividades de subsistência, ou permanecer nos antigos centros, a testemunhar o irremissivel apoucamento econômico.

\section{ANÁLISE DOS ASSENTOS PAROQUIAIS: VISÃO DE CONJUNTO}

Passemos, agora, à análise dos dados empíricos relativos aos registros de batismos, óbitos e casamentos da freguesia de Nossa Senhora da Conceição de Antônio Dias - como dissemos, uma de duas existentes, no período colonial, em Vila Rica.

O evolver dos três eventos assinalados apresentam, em termos gerais, comportamento similar no correr do século XVIII e início da décima nona centúria. A corresponder ao incremento (recesso) da atividade exploratória, observava-se o crescimento (decréscimo) das cifras correspondentes a mortes, consórcios e batizados. Evidentemente, as variações na atividade aurífera, de um lado, e nas quantidades referentes às variáveis demográficas em foco, por outro, não aparecem superpostas no tempo; os valores referentes a estas últimas mostram-se defasados por lapso temporal necessário aos ajustamentos decorrentes de processos biológicos e institucionais (Cf. gráfico 1).

\footnotetext{
10 MAWE, 1944, p. 177.
} 
Gráfico 1 - Número anual médio de casamentos, óbitos, batismos e exportação (produção) de ouro por períodos de 10 anos.

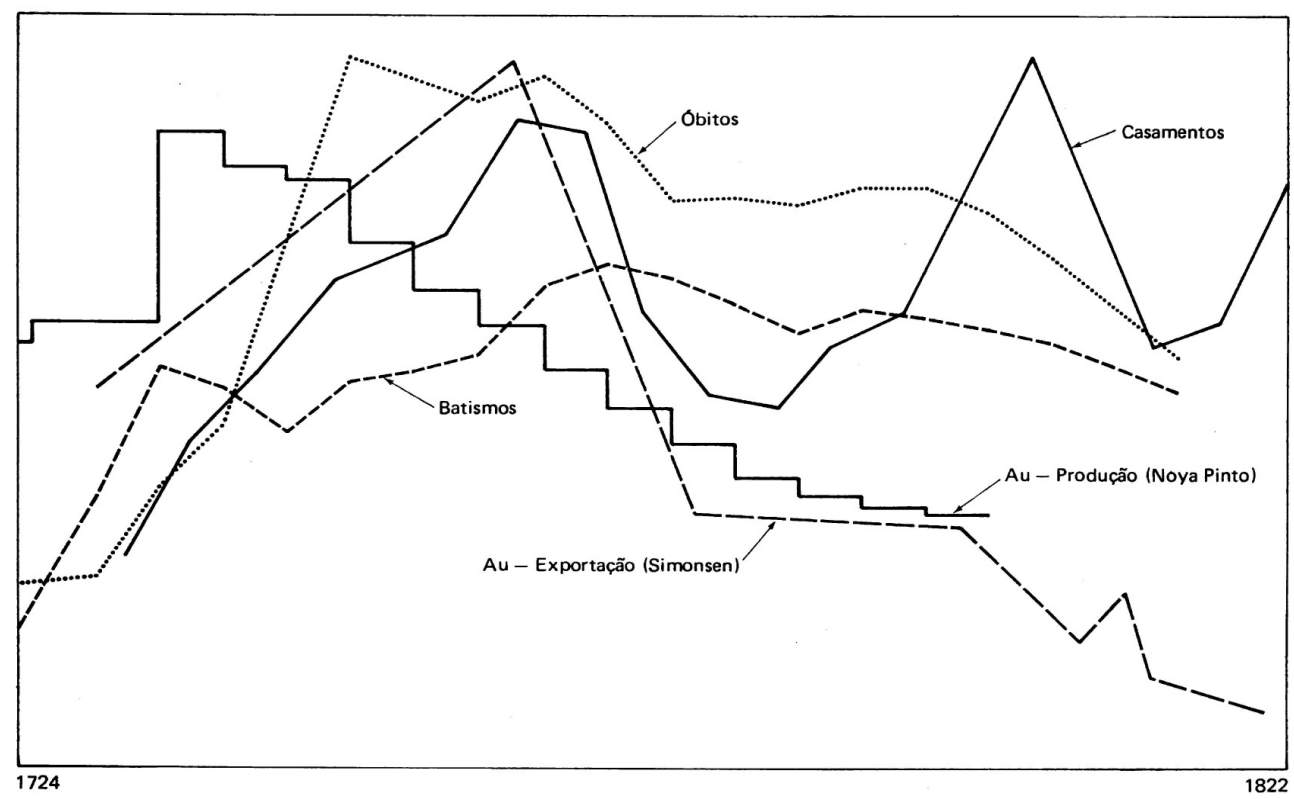

Destarte, observou-se rápido aumento no número de óbitos entre os decênios 1719/28 e 1744/53 - de u'a média anual equivalente a 61 defunções passou-se a quantidade quatro vezes superior (238 mortes por ano) no segundo intervalo temporal anotado. Altos níveis para os valores médios anuais verificaram-se até o decênio 1759/68; seguido de queda substancial na década 1769/78 - de 232 caiu-se a 191 mortes por ano. De então até o final do século XVIII configurou-se um patamar no qual observou-se estreita faixa de variação - entre o mínimo de 189 e o máximo de 196 óbitos anuais. De fins do século XVIII e início do XIX até o limite cronológico superior de nosso estudo (1818), apresentou-se persistente decréscimo na quantidade de falecimentos - de 196 mortes por ano (decênio 1789/98) passou-se a 137; quebra correspondente a pouco menos de um terço.

Os batismos mostraram lineamento muito próximo ao dos óbitos. De 47, em média, correspondentes à década 1719/28, passou-se para valor quatro vezes mais elevado no período 1764/73 - 170 batizados por ano -, desta cifra máxima passou-se, no decênio 1779/88, para média anual equivalente a 147 batismos. Deste último período ao compreendido pelos anos 1794/1803 configurou-se um patamar no qual a oscilação máxima foi de 4 batismos. De 1794/1803 ao fim do 
intervalo temporal em análise, observou-se queda substantiva na variável em pauta - de 147 passamos para 126 batismos anuais, em média, no decênio 1809/18, ou seja, quebra proporcional de $14,3 \%$.

Esboça-se, ao fim do período em estudo, o equilíbrio entre nascimentos e óbitos, prenúncio de relevante mudança no crescimento vegetativo da população de Antônio Dias - que, de negativo, como se mostrara por quase todo o século XVIII e início do XIX, passou a positivo nos últimos anos do primeiro quinto da décima nona centúria.

Como no caso de óbitos e batismos, a análise dos dados relativos à evolução dos casamentos evidencia, de imediato, períodos de acréscimo e queda no número de consórcios celebrados. Assim, de 1727 à década compreendida entre 1760/69, verificou-se substancial aumento na quantidade de uniões. De fins da década dos 60 à dos 80 os enlaces rarefizeram-se segundo taxa mais elevada do que a correspondente ao acréscimo verificado no período anterior.

Ao final dos anos 70 e em todo decênio dos 80 o número de casamentos estabilizou-se em torno da média prevalecente nos anos 30 e 40 - em 1786 o número de consórcios igualou-se ao registrado em 1737 e, em 1790, observou-se quantidade correspondente à média dos anos compreendidos entre 1732 e 1741. Dos anos 80 ao início do século XIX verificou-se rápida recuperação seguida de baixa que se estendeu até o segundo decênio do século.

Cuidemos, agora, dos principais condicionantes das variações observadas nos dados ora analisados. Ressaltam, desde logo, três fatores explicativos básicos, intimamente correlacionados.

Altamente relevante parece ter sido o grande afluxo e posterior retração numérica na entrada do elemento africano. Para D. Rodrigo da Costa, Governador do Brasil, ao voltar à Europa, em 1706, "representava caminhar o Estado para a ruína total, por faltarem os escravos, todos vendidos para as minhas, mal chegavam aos portos." 11

A população escrava de Vila Rica apresentou rápido incremento nas quatro primeiras décadas do século XVIII. Em 1716 contaram-se 6.721 cativos e, dois anos depois, 7.110; em 1728 a cifra subia a 11.521. Em 1735, segundo dados incorporados ao Códice Costa Matoso, o número de cativos atingia 20.863. Em 1743 somaram 21.746. A partir desse ano a tendência declinante mostrou-se evidente; em 1749 o número de escravos caíra a 18.293.

Com respeito aos cativos deve-se lembrar, ainda, sua alta taxa de mortalidade. Martinho de 
Mendonça, delegado da Coroa e conhecedor das condições reinantes em Minas relatava, no ano de 1734, que os senhores não esperavam conseguir, em média, mais de doze anos de trabalho dos escravos comprados ainda jovens. Com base no documento anônimo Considerações sobre as duas classes mais importantes de povoadores da Capitania de Minas Gerais, ${ }^{12}$ pode-se estabelecer que, grosseiramente, a taxa de mortalidade dos escravos estaria entre 50 e 66 mortes por mil cativos, índice muitíssimo elevado - segundo Roland Pressat: "seguramente, uma taxa bruta de 45 a 50 por mil constituiu um limite que não podia ser excedido sem comprometer a sobrevivência da espécie"13 - e em muito superior à taxa bruta de mortalidade - de 23,4 óbitos por mil habitantes - calculada para Vila Rica (Comarca) com base em dados referentes a 1776.

A estas considerações devemos juntar a alta taxa de mortalidade infantil relativa aos filhos de cativos. Em que pese a baixa fecundidade das escravas, dado seu grande número o peso relativo de nascimento (e, por consequência, de óbitos) de crianças escravas mostrava-se elevado. Fato a contribuir para 0 alto índice de mortalidade.

À afluência dos africanos deve-se aliar a rápida concentração, na área mineratória, de grande contingente de livres e escravos que se deslocaram do Reino e de outras partes do próprio território da Colônia.

O mais eloquente testemunho deste fenômeno legou-nos Antonil. No alvorecer do século XVIII, assim caracterizava, o jesuíta, as "pessoas que andam nas minas e tiram ouro dos ribeiros":

\begin{abstract}
"A sede insaciável do ouro estimulou a tantos a deixarem suas terras e a meterem-se por caminhos tão ásperos como são os das minas, que dificultosamente se poderá dar conta do número das pessoas que atualmente lá estão. Contudo, os que assistiram nelas nestes últimos anos por largo tempo, e as correram todas, dizem que mais de trinta mil almas se ocupam, umas em catar, e outras em mandar catar nos ribeiros do ouro, e outras em negociar, vendendo e comprando o que se há mister não só para a vida, mas para 0 regalo, mais que nos portos do mar.

"Cada ano, vêm nas frotas quantidade de portugueses e de estrangeiros, para passarem às minas. Das cidades, vilas, recôncavos e sertões do Brasil, vão brancos, pardos e pretos, e muitos índios, de que os paulistas se servem. A mistura é de toda a condição de pessoas: homens e mulheres, moços e velhos, pobres e ricos, nobres e plebeus, seculares e clérigos, e religiosos de diversos institutos muitos dos quais não têm no Brasil convento nem casa."14
\end{abstract}

A Coroa, alarmada com o despovoamento decorrente deste processo emigratório

\footnotetext{
11 AZEVEDO, 1973, p. 323.

12 ANÔNIMO, 1862, p. 421

13 PRESSAT, 1967, p. 79.

14 ANTONIL, s/d, p. 263-264.
} 
indiscriminado, resolveu refreá-lo e passou a exarar decretos e dispositivos legais dos quais a própria frequência evidencia a inocuidade.

Por seu lado, o movimento migratório colonial, de grandes proporções, chegou a abalar a economia agrícola preexistente. "Na borda marítima da colônia, o êxodo, motivado pela atração das minas, teve consequências deploráveis. Despovoavam-se as terras, não só da gente livre, que acorria à aventura, mas principalmente dos escravos sem os quais não havia lavoura nem indústria possíveis" - afirma João Lúcio de Azevedo. ${ }^{15}$

A alimentar tamanho deslocamento populacional, como nos lembra Celso Furtado, estava a própria forma de ocorrência do metal precioso: "Dadas suas características, a economia mineira brasileira oferecia possibilidades a pessoas de recursos limitados, pois não se exploraram grandes minas - como ocorria com a prata no Peru e no México - e sim o metal de aluvião que se encontrava depositado no fundo dos rios."16

Este característico e a relativa pobreza do solo na área mineratória, em geral, e em torno de Vila Rica, em particular, dão-nos o embasamento do terceiro fator explicativo do evoluir das variáveis em estudo: com a decadência da atividade mineratória, a população, sobretudo a parcela livre, tendeu a deslocar-se para novas áreas a procura de ouro, ou, em momento mais tardio - quando esgotado o estoque aurífero acumulado milenarmente -, a demandar terra mais rica que the pudesse garantir o sustento, baseado, agora, na lide agrícola.

Subjacente ao processo demográfico analisado sempre esteve presente, pois, a atividade exploratória. Justamente esta conclusão deriva do confronto entre as variações referentes ao número de casamentos, óbitos e batizados e as relativas ao montante extraído de ouro, conforme patenteado no Gráfico 1.

\section{CASAMENTOS: $1727 / 1826$}

Com respeito aos casamentos, caso se segmente a população em estratos correspondentes a livres, forros e escravos, reconhecemos, associado a cada subconjunto, comportamento diverso. Assim, o evoluir dos consórcios referentes a escravos e forros apresenta grande similitude. Ambos os grupos - o primeiro mais do que o segundo - revelaram-se altamente correlacionados à atividade

\footnotetext{
${ }^{15}$ AZEVEDO, 1973, p. 322.

16 FURTADO, 1970, p. 74.
} 
aurífera em todo o período analisado, enquanto a evolução dos casamentos de livres ganha autonomia - com respeito à extração do ouro - a partir do último quinto do século XVIII. Assim, distinguem-se claramente os escravos dos livres e, em posicionamento intermediário, dispõem-se os forros (ver Gráficos 2 e 3).

Gráfico 2 - Número anual médio de casamentos por períodos de 10 anos e exportação, produção de ouro.

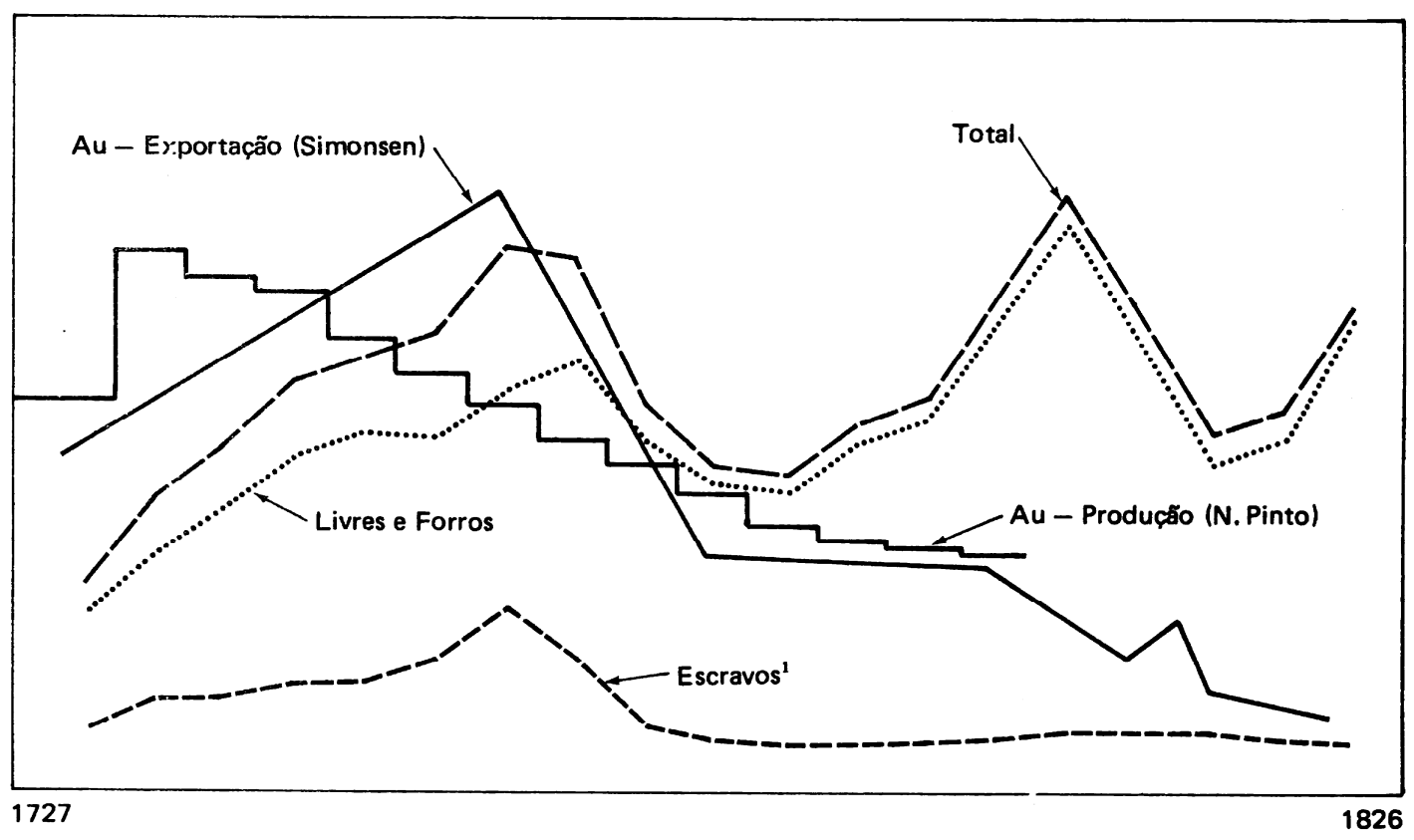

obs.: (1) pelo menos um cônjuge escravo.

Além dos empecilhos decorrentes de maneira imediata do maior ou menor dinamismo da atividade exploratória, ocorriam, também, condicionantes de ordem institucional.

Assim, a par das diferentes vivências relativas aos estratos sociais componentes da sociedade brasileira colonial, derivam-se limitações colocadas pelo próprio mecanismo imposto pela Igreja à consecução do sacramento indispensável à legitimação dos consórcios. Óbices advindos, por um lado, do procedimento formal exigido para se conseguir a autorização necessária para que fosse celebrado o casamento e, por outro, dos custos monetários associados às prescrições ditadas pelo poder espiritual. Nesse sentido parecem-nos elucidativos os juízos expendidos, no início do século XIX, por Saint-Hilaire:

"O vigário da vara [...] é juiz dos casamentos, e não se pode contrair nenhum sem o seu consentimento. Ainda que as partes estejam perfeitamente de acordo é necessário que tenha lugar um processo perante o vigário da vara, e o resultado dessa ação bizarra é uma 
provisão que se paga por 10 ou $12 \$ 000$ réis ou mais, e que autoriza o cura a casar os nubentes [...]. Assim, em um país onde já existe tanta repugnância pelas uniões legítimas, e onde seria tão essencial para o Estado e a moralidade pública que elas fossem encorajadas, os indigentes são, por assim dizer, arrastados pela falta de recursos a viver de modo irregular."17

Gráfico 3 - Número anual médio de casamentos, por períodos de 10 anos, e exportação, produção de ouro.

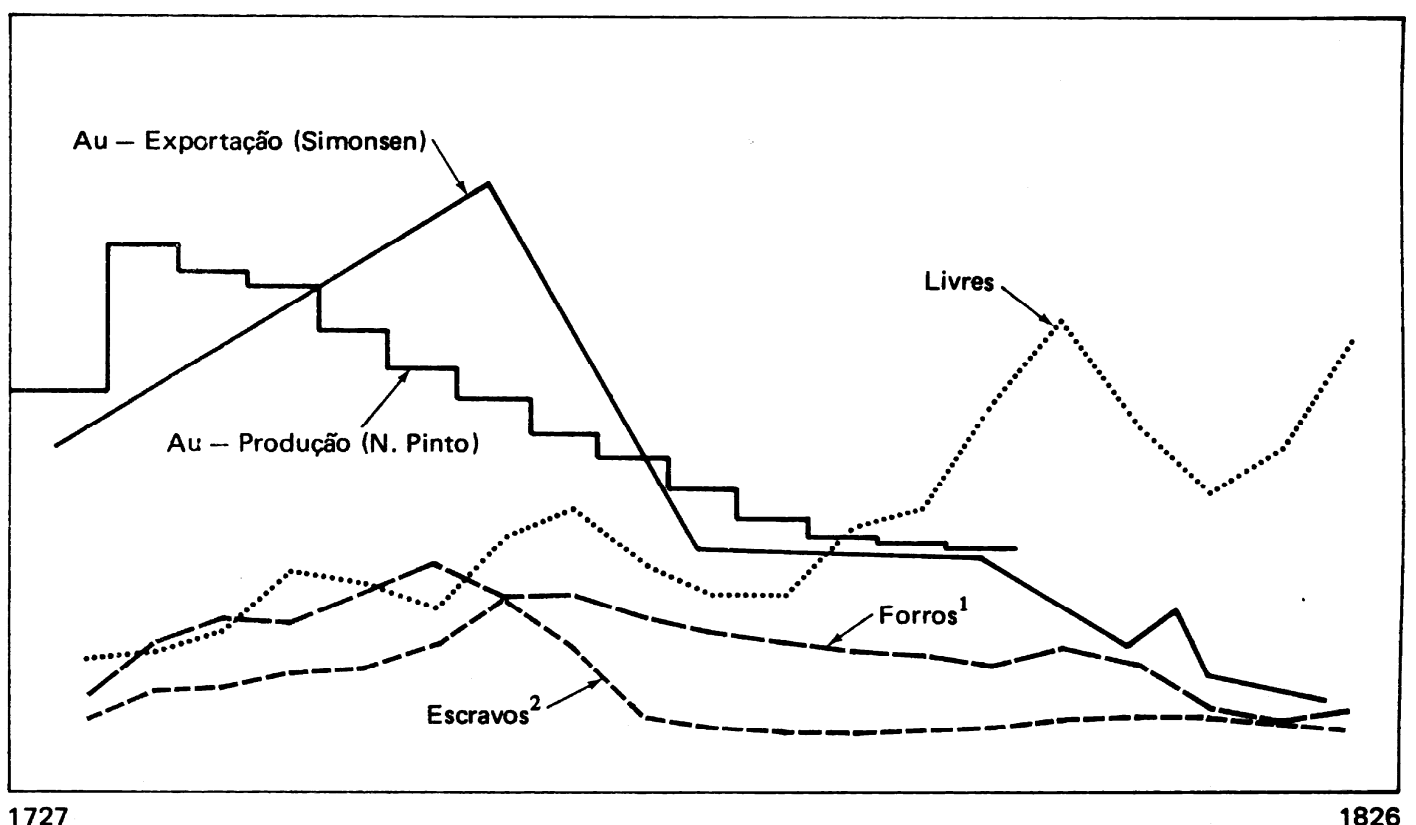

obs.: (1) pelo menos um cônjuge forro.

(2) pelo menos um cônjuge escravo.

Quanto aos segmentos populacionais aludidos, verificou-se que os consórcios "dentro" do mesmo segmento prevaleceram sobre as uniões entre indivíduos de "diferentes" grupos populacionais (ver Tabela 1). Por outro lado, não encontramos rigidez absoluta com respeito aos casamentos entre indivíduos de grupos distintos; não se verificou casamento a reunir escravos e livres, mas o número de consórcios entre escravos e forros parece-nos altamente significativo (ver Tabela 2).

Alguns dos casamentos a envolver libertos e escravos são muito sugestivos e trazem subsídios ao entendimento do papel representado pelo escravismo na sociedade brasileira. Evidentemente, são casos isolados mas que, justamente por sua excepcionalidade, emprestam colorido ao quadro, por vezes esquemático, que se construiu das relações pessoais e entre as 
camadas sociais então vigentes.

Ocorriam, por exemplo, consórcios entre senhores e seus próprios cativos. Deste feitio foi 0 enlace de "Garcia Pedroso preto forro com Maria da Costa também preta sua escrava" celebrado aos 15 de novembro de 1744; dois meses depois, aos 9 de janeiro de 1745, celebrava-se a união de "Tomás de Freitas preto de nação Mina escravo da contraente, Ana de Jesus, com a dita Ana de Jesus preta forra de nação Guiné".

TABELA 1

Casamentos segundo a condição social dos cônjuges

\begin{tabular}{|c|c|c|c|c|c|}
\hline \multirow{2}{*}{ ESPOSA } & \multicolumn{4}{|c|}{ ESPOSO } & \\
\hline & Livres & Forros & Escravos & Indeterminados & \\
\hline Livres & 957 & $\begin{array}{c}20 \\
(60,16)\end{array}$ & $\begin{array}{r}0 \\
(1,26)\end{array}$ & $\begin{array}{ll} & 0 \\
--\end{array}$ & -- \\
\hline Forras & $\begin{array}{c}55 \\
(3,46)\end{array}$ & $\begin{array}{c}351 \\
(22,07)\end{array}$ & & $\begin{array}{c}38 \\
(2,38)\end{array}$ & $\begin{array}{c}1 \\
(0,06)\end{array}$ \\
\hline Escravas & $\begin{array}{l}0 \\
-.\end{array}$ & $\begin{array}{c}12 \\
(0,75)\end{array}$ & $(9,44)$ & $\begin{array}{l}150 \\
--\end{array}$ & 0 \\
\hline Indeterminadas & $(0,06)$ & $\begin{array}{c}1 \\
(0,24)\end{array}$ & 4 & $\begin{array}{r}0 \\
(0,12)\end{array}$ & 2 \\
\hline
\end{tabular}

OBS:: Os números entre parênteses são porcentagens.

Fonte: Para todas as tabelas, os dados empíricos procedem dos códices da Freguesia de Nossa Senhora da Conceição de Antônio Dias e referem-se ao período 1727/1826.

TABELA 2

Casamentos a envolver pelo menos um cônjuge escravo

\begin{tabular}{lcc} 
& & \multicolumn{1}{c}{ ESPOSO } \\
\cline { 2 - 3 } ESPOSA & Forro & Escravo \\
\hline Forra & 0 & 38 \\
& -- & $(19,0)$ \\
Escrava & 12 & 150 \\
& $(6,0)$ & $(75,0)$ \\
\hdashline$-\cdots-\cdots$
\end{tabular}

OBS.: Os números entre parênteses são porcentagens.

Aos cinco de maio de 1740 acontecia outro casamento sui generis: "... na minha presença se casaram por palavras de presente Brás Gonçalves negro Angola escravo de Joana Fernandes 
Lima com Juliana Fernandes Lima filha da dita Joana Fernandes crioula forra..."

Em termos de estrato social e cor - considerados os três segmentos populacionais aludidos -, verificou-se, quanto à escolha do parceiro, mais "liberdade de opção" para o sexo masculino, em geral, e para os homens livres, em particular. 0 estudo das médias mensais de consórcios revelou variações sazonais devidas às posturas religiosas contrárias a casamentos durante a Quaresma e 0 Advento. Em relação ao local de origem dos cônjuges, nascidos e/ou batizados no Brasil, registrouse menor mobilidade da massa feminina; quanto ao fluxo imigratório, apresentou-se predominante 0 elemento masculino.

\section{BATISMOS: $1719 / 1818$}

Como já salientamos, o comportamento das variáveis demográficas apresentou-se distinto quando considerados os segmentos populacionais relativos a livres, forros e escravos. Assim, enquanto os batismos de livres mostraram tendência ascendente até a década 1799/1808 verificando-se, a seguir, ligeira queda, devida, ao que parece, à emigração dos habitantes de Vila Rica -, os valores relativos aos batizados de escravos, depois de subirem rapidamente nas primeiras quatro décadas do século XVIII, tenderam a declinar gradativamente (ver Gráfico 4)..

Gráfico 4 - Número anual médio, por períodos de 10 anos, de batismos, segundo a condição social.

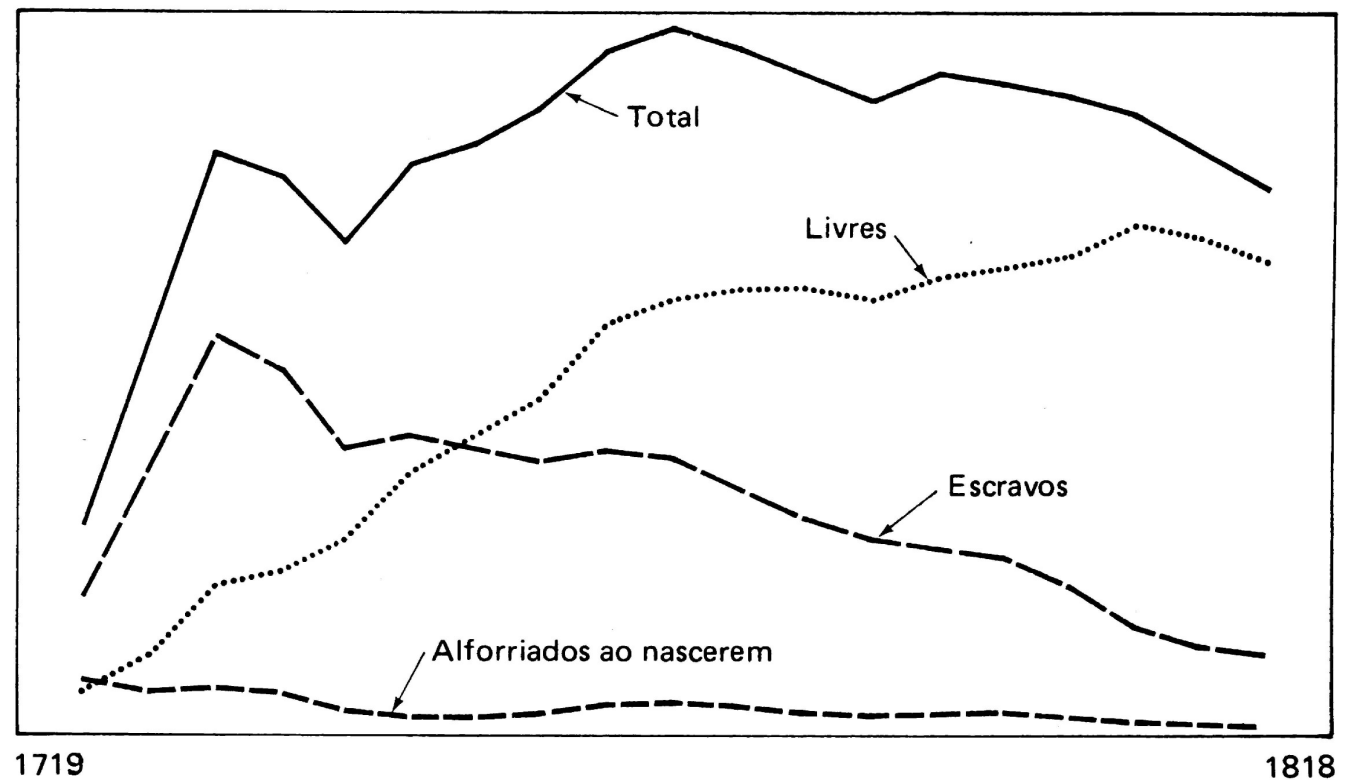

Tais movimentos divergentes deveram-se a três condicionantes: à quebra no número de 
escravos entrados na área; à afluência de livres, notadamente nas primeiras décadas do século XVIII e, por fim, à concessão ou compra de alforria, processo este que engrossava o contingente de crianças nascidas livres

Atenhamo-nos, agora, aos expostos; recém-nascidos abandonados à porta de residências particulares, igrejas ou do Senado da Câmara. O conhecimento do evoluir no tempo do número e peso relativo dos enjeitados mostra-se importante porque nos permite lançar luz sobre as condições econômicas gerais das comunidades estudadas; espera-se, nos períodos de dificuldade econômica ou empobrecimento persistente, o aumento do peso relativo dos expostos. No período em foco, verificou-se incremento continuado no número dos expostos até a década 1799/1808; tal aumento numérico assumiu caráter dramático - de 4 enjeitados batizados no decênio 1724/33 atingiu-se a cifra de 167 na década 1799/1808. Desta última ao espaço de tempo compreendido entre 1809 e 1818 observou-se ligeira queda - de 167 passou-se a 129 - decorrente, com certeza, do processo emigratório que abatia a população ouro-pretana.

Referentemente ao peso relativo dos enjeitados sobre o total de batismos verificou-se movimento igualmente significativo - de $0,45 \%$ na década $1724 / 33$ chegou-se a cifras que giravam em torno de $11 \%$ no intervalo $1779 / 1818$. Este incremento representa um dos aspectos do impacto, sobre as variáveis demográficas, da decadência da atividade mineratória (ver Gráfico 5).

Gráfico 5 - Porcentagem de expostos sobre o total de batismos.

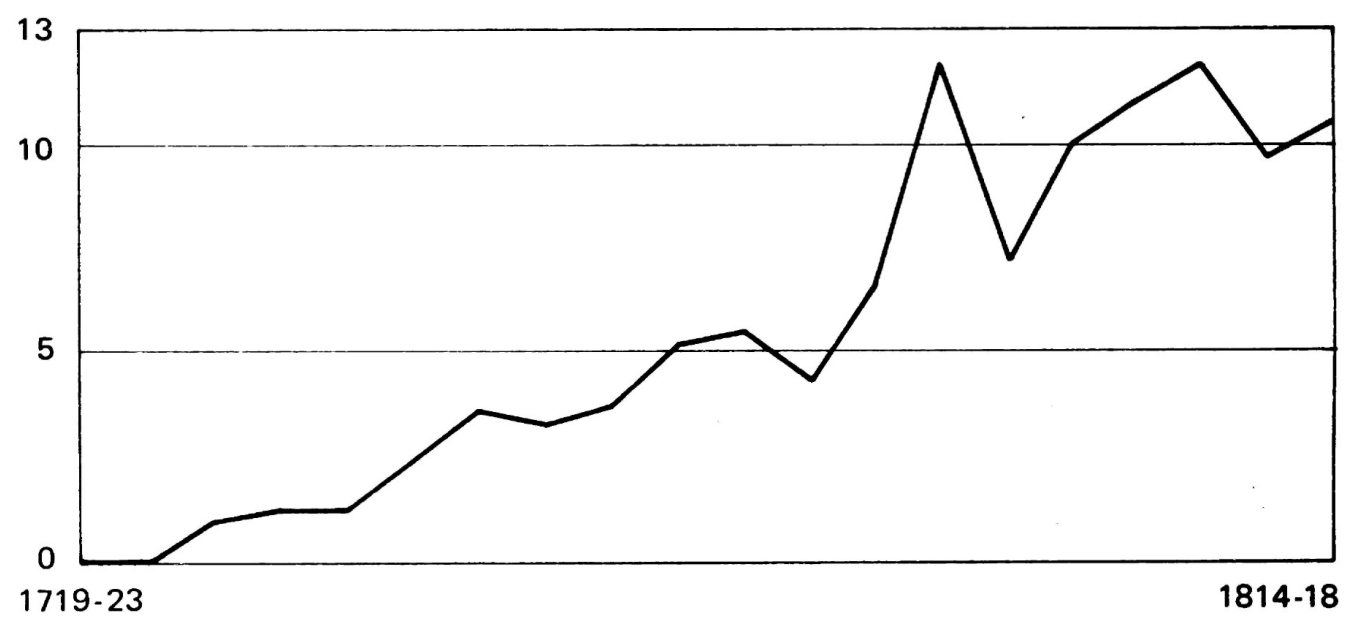




\section{ÓBITOS: $1719 / 1818$}

Quanto aos óbitos, ressalta, desde logo, o estreito liame entre o lineamento do evoluir das defunções de cativos e as quantidades extraídas de ouro. Quanto às mortes de alforriados verificouse, até a década 1774/83, rápido movimento ascendente seguido de patamar que se estendeu até 0 último decênio do século XVIII, para, subsequentemente, revelar-se tendência decrescente condicionada, sobretudo, pelo decremento observado no número de novos escravos encaminhados a Vila Rica.

Gráfico 6 - Número anual médio, por períodos de 10 anos, de óbitos (segundo a condição social) e produção de ouro.

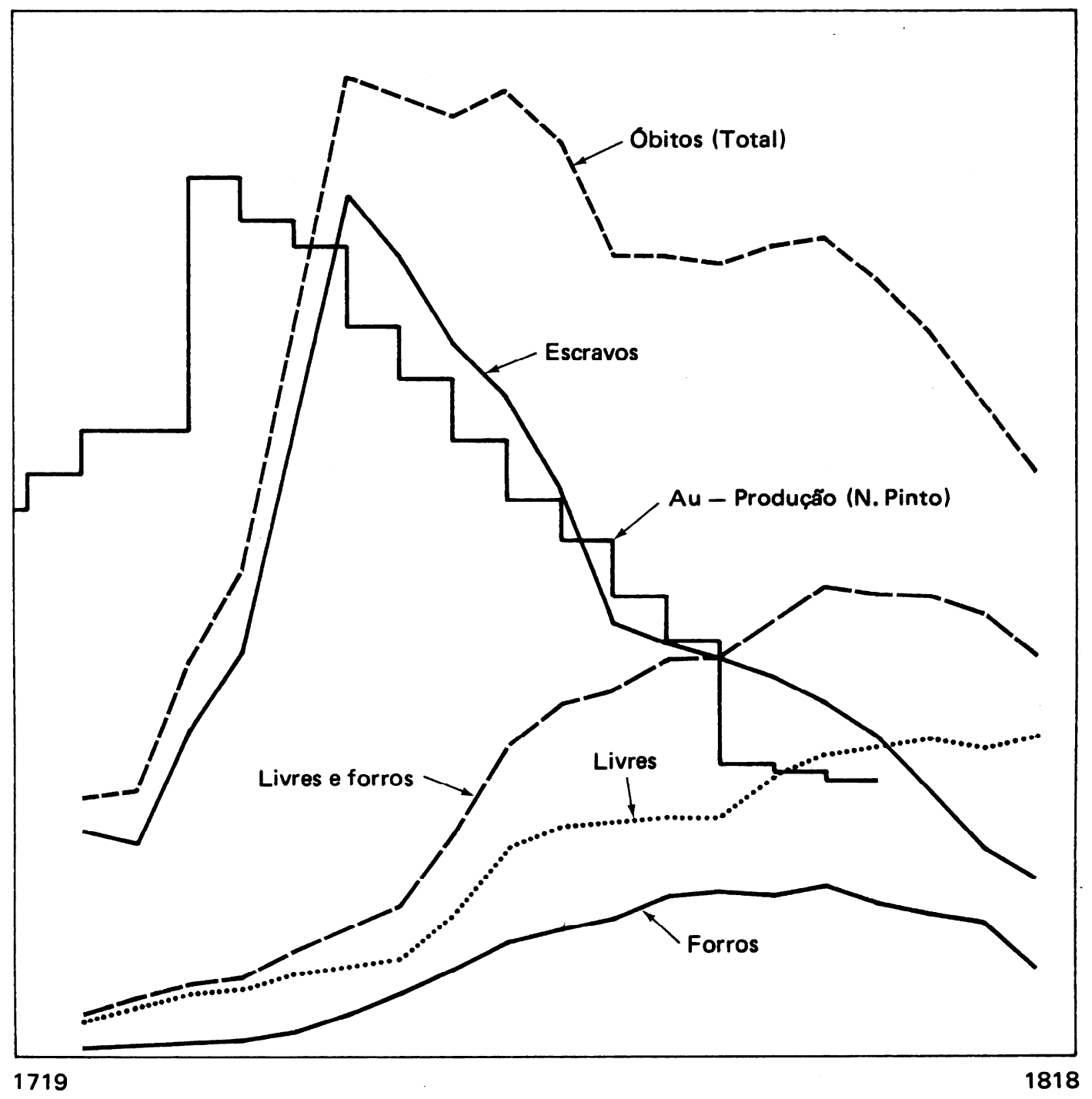


O evolver dos óbitos de livres expressa, também, os percalços da economia mineira; num primeiro momento, em função da grande concorrência de pessoas para a área mineratória no auge da atividade aurífera, observou-se rápido incremento no número de mortes de livres - de 42 óbitos ocorridos na década 1719/28 passou-se, no decênio 1764/73, para 543 -, acréscimo correspondente a mais de $1.200 \%$. A seguir observou-se um patamar que se estendeu até o período 1779/88. Deste último decênio até o início do século XIX verificou-se um acréscimo condicionado, sobretudo, pelas gerações livres de pais forros. Por fim, apresentou-se novo patamar, decorrente, a nosso ver, da diáspora populacional já referida (ver Gráfico 6 acima).

\section{REFERÊNCIAS BIBLIOGRÁFICAS}

1. ANÔNIMO. Áureo Trono Episcopal, colocado nas Minas de Ouro. Publicado por Francisco Ribeiro da Silva, Lisboa: Oficina de Miguel Manescal da Costa, 1749.

2. ANÔNIMO. Considerações sobre as duas classes mais importantes de povoadores da Capitania de Minas Gerais, como são as de mineiros e agricultores, e a maneira de as animar, Revista do Instituto Histórico Geográfico e Etnográfico do Brasil, Tipografia de Luiz dos Santos, Rio de Janeiro, 1862, tomo XXV, III trimestre de 1862.

3. ANTONIL, André João. Cultura e Opulência do Brasil. Introdução e Vocabulário por A. P. Canabrava, 2a. ed., São Paulo: Ed. Nacional, s/d., (Roteiro do Brasil, 2).

4. AZEVEDO, João Lúcio de. Épocas de Portugal Econômico -- Esboços de História, 3a. ed., Lisboa: Livraria Clássica Editora, 1973.

5. CANABRAVA, Alice Piffer. João Antônio Andreoni e sua Obra, in ANTONIL, André João. Cultura e Opulência do Brasil. Introdução e Vocabulário por A. P. Canabrava, 2a. ed., São Paulo: Ed. Nacional, s/d., (Roteiro do Brasil, 2).

6. FURTADO, Celso. Formação Econômica do Brasil, 10a. ed., São Paulo: Ed. Nacional, 1970.

7. GONZAGA, Tomás Antônio. Cartas Chilenas, Biblioteca Nacional. Disponível em: http://www.biblio.com.br/defaultz.asp?link=http://www.biblio.com.br/conteudo/TomasAntonioGonzaga/cartaschilenas.htm . Acesso em 24/08/2011.

8. MACHADO, Simão Ferreira. Triunfo Eucarístico. Exemplar da Cristandade Lusitana. Lisboa: Oficina da Música, 1734.

9. MAWE, John. Viagens ao Interior do Brasil, Rio de Janeiro: Zélio Valverde, 1944.

10. PRADO JÚNIOR, Caio. História Econômica do Brasil. 5a. ed., São Paulo: Brasiliense, 1959.

11. PRESSAT, Roland. El análissis demográfico - métodos, resultados, aplicaciones, México D.F.: Fondo de Cultura Econômica, 1967.

12. SAINT-HILAIRE, Auguste de. Viagem pelas Províncias do Rio de Janeiro e Minas Gerais. São Paulo: Itatiaia e EDUSP, 1975, (Coleção Reconquista do Brasil, 4).

\section{Artigo recebido em: 24/08/2011}

Aprovado para publicação em: 12/09/2011 